\title{
An early developmental vertebrate model for nanomaterial safety: bridging cell-based and mammalian toxicity assessment
}

\begin{abstract}
Aim: With the rise in production of nanoparticles (NPs) for an ever-increasing number of applications, there is an urgent need to efficiently assess their potential toxicity. We propose a NP hazard assessment protocol that combines mammalian cytotoxicity data with embryonic vertebrate abnormality scoring to determine an overall toxicity index. Results: We observed that, after exposure to a range of NPs, Xenopus phenotypic scoring showed a strong correlation with cell based in vitro assays. Magnetite-cored NPs, negative for toxicity in vitro and Xenopus, were further confirmed as nontoxic in mice. Conclusion: The results highlight the potential of Xenopus embryo analysis as a fast screening approach for toxicity assessment of NPs, which could be introduced for the routine testing of nanomaterials.
\end{abstract}

First draft submitted: 1 October 2015; Accepted for publication: 21 December 2015; Published online: 22 March 2016

Keywords: cytotoxicity • in vitro-in vivo correlations $\bullet$ nanomaterials $\bullet$ nanomedicine - nanotoxicity $\bullet$ Xenopus laevis

\section{Background}

Objects at nanoscale $(<100 \mathrm{~nm})$ take on novel characteristics due to their small size and extensive surface area, providing markedly different properties to develop reagents for biomedicine. As such, nanomaterials are being developed for an ever-increasing number of diseases including; infectious diseases, hepatitis, cardiac and vascular disorders, immune and degenerative diseases, and cancer [1]. However, their high surface area-tovolume ratio renders nanoparticles (NPs) highly reactive, which can result in toxicity within biological systems [1-3]. At present a dedicated regulatory framework for testing nanomedicines does not yet exist and cellbased assays are the current method of choice despite poor in vitro-in vivo correlations of nanomaterial toxicity [4]. Despite the increase in number of publications in nanomedicine over the past $5-10$ years $[5,6]$, it is often difficult to obtain conclusive results on the toxicity of engineered nanomaterials, which is due to poor physico-chemical characterization of the material and a distinct lack of standardized protocols [7]. This is seriously hampering the transfer of many promising nanomedicines to the clinic.

Safety assessment is a necessary step in the process to develop a novel nanomedicine and should involve further refinement at early stages in NP development to guarantee appropriate safety. Learning from the development of first-generation nanomedicines that have been used in clinical procedures for years $[8]$ and have been tested using the standard procedures for the evaluation of all drugs [9], it is desirable to develop methods that are tailored to evaluating specific toxicities associated with nanomaterials. Recently, much effort from the nanocommunity has been directed to optimize protocols that assess the safety of nanomaterials. This concept is known as 'safety by design' [5] and is crucial for the production of nanomedicines, for which engineering at the nanoscale can
Carl A Webster ${ }^{1}$, Desire Di Silvio', Aarthi Devarajan', Paolo Bigini ${ }^{3}$, Edoardo Micotti ${ }^{3}$, Chiara Giudice ${ }^{4}$, Mario Salmona ${ }^{3}$, Grant $\mathrm{N}$ Wheeler ${ }^{2}$, Victoria Sherwood $* *, 1,5$ \& Francesca Baldelli Bombelli*,1,6

'School of Pharmacy, University of East Anglia, Norwich, UK

${ }^{2} 5$ chool of Biological Sciences, University of East Anglia, Norwich, UK ${ }^{3}$ IRCCS-Istituto di Ricerche Farmacologiche 'Mario Negri', Milan, Italy ${ }^{4}$ DIVET, Università degli Studi di Milano, Milan, Italy

${ }^{5}$ Skin Tumour Laboratory, Jacqui Wood Cancer Centre, University of Dundee, Dundee, UK

${ }^{6}$ Department of Chemistry, Materials and Chemical Engineering "G.Natta", NFMLab, Politecnico di Milano, Milano, Italy

*Author for correspondence: francesca.baldelli@polimi.it

**Author for correspondence: v.sherwood@dundee.ac.uk 


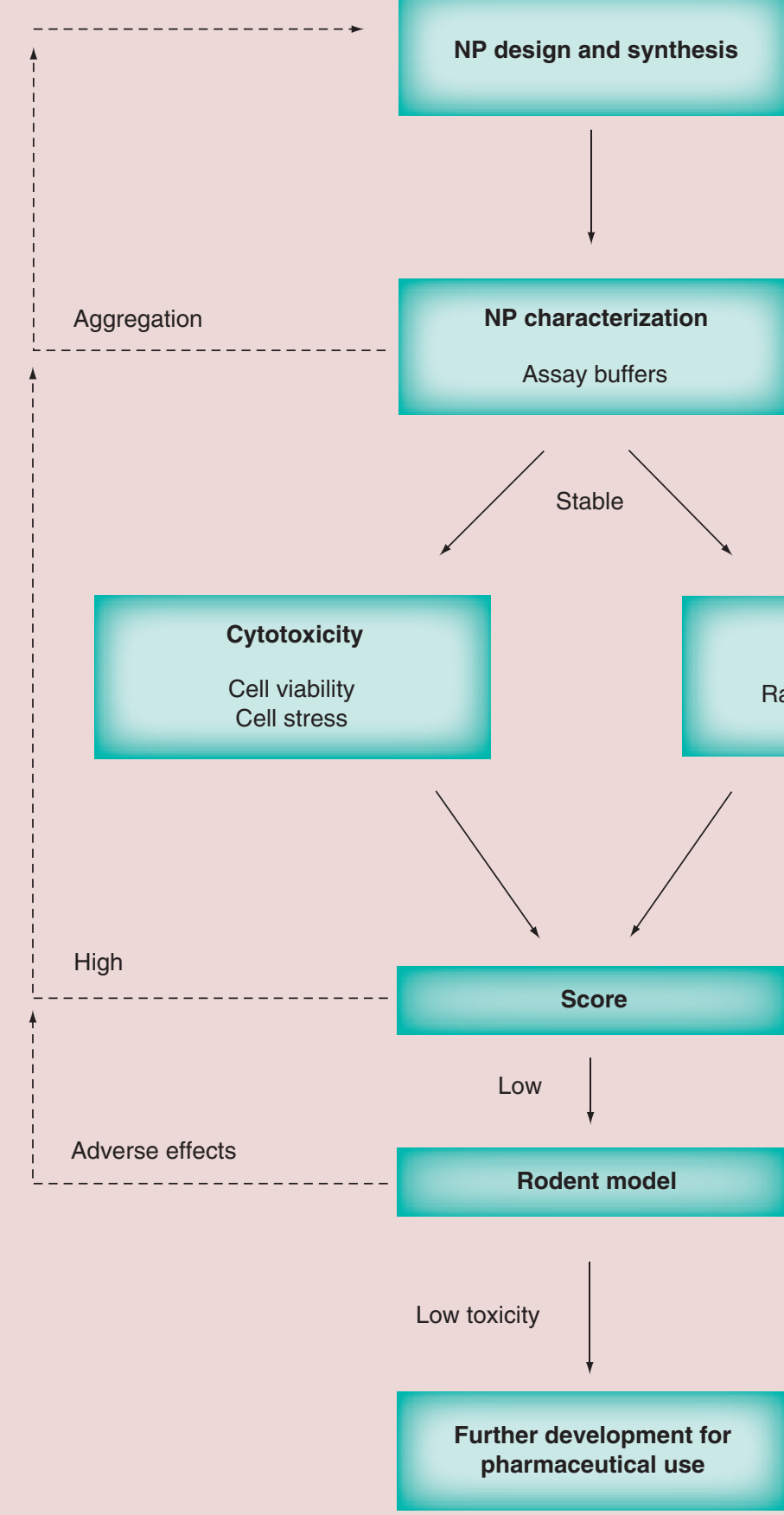

Figure 1. Nanotoxicity screening assay workflow. A novel NP is characterized in assay buffers, cell (RPMI) and embryo (0.1 × MMR) culture media. Unstable or aggregating NPs can be redesigned or altered through surface modifications. Once a stable NP is fully characterized, an integrated protocol combining cytotoxicity screens in a range of cell types (cell viability and cell stress) and Xenopus laevis ranking of phenotype abnormalities is applied in parallel. The results are combined to produce a score that indicates if the NPs should be applied in a rodent model and further developed for pharmaceutical use. MMR: Marc's modified ringers; NP: Nanoparticle.

cause unpredictable biological responses [10]. A compromise has to be met in order to produce nanoma- terials with desired properties (which for targeted treatments are often multifaceted, complex formula- 
tions), with tolerable toxicity and thus there is a need for robust screening methodologies at an early stage in NP development. Currently, the field requires a system that can bridge the safety assessment of NPs in cellbased assays with reliable data generated from mammalian in vivo toxicity assessment, providing stronger correlations between the two toxicological models.

A preclinical screening tool that effectively assesses toxicity of nanomedicines prior to mammalian models will enormously reduce the number of materials that need to be tested in higher vertebrate systems, while also improving the success rates of novel nanomaterials to pass mammalian toxicity assessment models. Most new generation nanomedicines are multicomponent systems with complex chemical structures, joining the properties of different materials in one unique engineered object, often involving the use of non-FDA approved materials. Therefore, there is a clear need to test the toxicity of the engineered nano-object at different stages of production. Thus, one consequence of generating multicomponent NPs for biomedical purposes is the potential of having to use a larger number of mammals for safety assessment than for the development of conventional drugs. It would be advantageous to test NP toxicity using a system that can bridge the gap in generating consistent data between in vitro cell-based assays and mammalian models of toxicity assessment [11,12]. Early developmental vertebrate models such as Danio rerio (zebrafish) and Xenopus laevis (African clawed frog) provide rapid and inexpensive systems for NP toxicity assessment, compared with adult mammalian models [11,13-15]. X. laevis produce embryos in sizeable quantities (adaptable for high-throughput screening) that are relatively large $(\sim 1 \mathrm{~mm}$ in diameter at early stages of embryonic development), making them highly suitable in vivo systems for the assessment of toxicants. X. laevis has a long-running history in toxicity testing, such as the frog teratogenesis assayXenopus (FETAX), which provides strong prediction of teratogens in mammals [16]. In addition they provide a means to investigate the toxicity of materials on whole organs, post organogenesis, to better simulate an adult model. Further advantages of using $X$. laevis as an in vivo toxicity model, include external development of the embryo to allow for temporal control over the exposure to NPs and facilitating investigation into toxic effects at critical stages of embryogenesis, such as gastrulation and neuralation. Furthermore, $X$. laevis developmental stages are well characterized making it an ideal model for phenotypic assays $[17,18]$. The sensitivity of embryos during development can be exploited to identify varying degrees of toxicity by a range of phenotypic abnormalities, providing an indication into safe dosages; information that historically is not accurately known before assessment in mammalian models.

In this study, we propose to use $X$. laevis embryos in combination with in vitro testing in mammalian cell lines to provide a multitiered, rapid and low cost approach to assess NP toxicity prior to in vivo mammalian testing. We have developed a methodology that assesses the toxicity of nanomaterials at an early stage in their production, before further assessment for translational applications (Figure 1). The methodology combines a full physicochemical characterization of the nanomaterial with quick and inexpensive in vitro cytotoxicity assays, and analysis in $X$. laevis embryos at different developmental stages, prior to mammalian testing.

\section{Methods}

NP synthesis \& characterization

$\mathrm{NH}_{2}-\mathrm{Fe}_{3} \mathrm{O}_{4}$ and PS-COOH NPs were commercially available and therefore bought from Nanocs (product code MP25-AM) and Invitrogen (product code F-8887), respectively. CdSe QDs and PEG- $\mathrm{Fe}_{3} \mathrm{O}_{4} \mathrm{NPs}$ were synthesized in-house. All NPs were fully characterized as described in the Supplementary Information. In addition, details about cell culture, all mouse procedures and statistical information is provided in the Supplementary Section.

\section{Trypan blue exclusion assay}

Cells were cultured as described in the Supplementary Information. A549 and SK-MEL-28 lines were seeded at $26,550 \mathrm{cells} / \mathrm{ml}$ and MDCK at 20,000 cells $/ \mathrm{ml}$ in 24 well-plates for trypan blue exclusion assay, which was carried out as previously described [19]. After attachment overnight, cells were exposed to different concentrations of NPs for $72 \mathrm{~h}$ before analysis.

\section{MTT assay}

Cell viability after exposure to NPs was assessed by MTT, as previously described [20]. Cells were seeded in 96-well plates at an initial density of 4500 cells/well and exposed to NPs for $72 \mathrm{~h}$. Cell viability was calculated as a ratio of mean absorbance from quadruplicate readings, normalized to nonstimulated cells.

\section{Immunoblotting}

Cells were lysed in $50 \mathrm{mM}$ Tris- $\mathrm{HCl}(\mathrm{pH} 7.5), 1 \%$ Triton $\mathrm{X}-100,150 \mathrm{mM} \mathrm{NaCl}$ and spun at $16,000 \times \mathrm{g}$ for $30 \mathrm{~min}$ at $4^{\circ} \mathrm{C}$. Immunoblotting was performed as previously described [21] using 1:1000 anti-PARP-1 (Santa Cruz Biotechnology) and 1:5000 anti-rabbit (Cell Signaling) antibodies, in 5\% BSA. 


\section{$X$. laevis phenotypic assay}

All experiments were performed in compliance with the relevant laws and institutional guidelines at the University of East Anglia. The research has been approved by the local ethical review committee according to UK Home Office regulations. X. laevis embryos were obtained as previously described [22,23]. Embryos were staged using the Nieuwkoop and Faber (NF) normal table of Xenopus development [24]. Embryos developed at $18^{\circ} \mathrm{C}$ until they reached the required stage. Embryos (5 per well) were placed in a 24-well plate and exposed to NPs. Once at the required stage, embryos were washed twice with PBS before fixing in MEMFA (3.7\% formaldehyde $1 \times$ MEM salts, MQW [1:1:8]) overnight at $4^{\circ} \mathrm{C}$. A further two PBS washes of the embryos was performed before embryos were scored for phenotypic abnormalities.

\section{$X$. laevis whole mount florescence microscopy}

NF stage $38 X$. laevis embryos were exposed to $10^{15} \mathrm{NP} /$ $\mathrm{ml}$ PS-COOH until NF stage 45 and anaesthetized with $0.6 \mathrm{mg} / \mathrm{ml}$ ethyl 3-aminobenzoate methanesulfonate salt (Sigma Aldrich). PS-COOH NPs were imaged in the bloodstream of anaesthetized embryos using Nikon Eclipse 600 with a CCD digital camera, with an emission filter of 509-547 nm.

\section{$X$. laevis transmission electron microscopy (TEM) imaging}

Embryos exposed to $10^{15.3} \mathrm{NP} / \mathrm{ml}$ PEG- $\mathrm{Fe}_{3} \mathrm{O}_{4}$ during NF stage 38 to NF stage 45 were euthanized, fixed, embedded and sectioned as previously described [25]. Sections were observed using a Tecnai 20 TEM with AMT cameras, operating at an acceleration voltage of $200 \mathrm{kV}$.

\section{Results}

\section{NP synthesis \& characterization}

Our proposed nanotoxicity testing protocol (Figure 1) has been tested using four different NPs; CdSe quan- tum dots (QD) NPs, pegylated magnetite NPs $\left(\mathrm{Fe}_{3} \mathrm{O}_{4}-\right.$ PEG), amine-functionalized magnetite $\mathrm{NPs}\left(\mathrm{Fe}_{3} \mathrm{O}_{4}\right.$ $\mathrm{NH}_{2}$ ) and fluorescent carboxylated polystyrene NPs (PS-COOH), selected for: a putative highly toxic NP as a positive control (QDs); two iron-oxide NPs (possible MRI contrast agents), with different surface functionalization and physical chemical stability to test the ability of the protocol to detect potential differences in toxicity based on NP modifications [26,27]; and a negatively charged NP (PS-COOH) [28], being part of the first group of materials to be evaluated for safety at the nanoscale. Both QD and $\mathrm{Fe}_{3} \mathrm{O}_{4}$-PEG NPs were synthesized and purified in-house as explained in the material and methods section, while PS-COOH and $\mathrm{Fe}_{3} \mathrm{O}_{4}-\mathrm{NH}_{2} \mathrm{NPs}$ were bought from specific suppliers and further characterized.

NP characterization is an essential first step in our protocol design (Figure 1). TEM and mean core sizes for the NPs are reported in Table 1, while statistical analysis of the size together with representative images are shown in Supplementary Figure 1 in the Supplementary data section. NPs were also characterized by dynamic light scattering (DLS) and $\zeta$-potential in aqueous dispersions (except for the $\mathrm{Fe}_{3} \mathrm{O}_{4}$ - $\mathrm{PEG}$ NPs that were dispersed in PBS) which showed that hydrodynamic diameters were generally larger than TEM core sizes and that hydrodynamic sizes for QD and $\mathrm{Fe}_{3} \mathrm{O}_{4}-\mathrm{NH}_{2}$ NPs indicated the formation of NP clusters to some extent (Supplementary Figure 2A). NP stability and aggregation behaviors were studied in the embryo (0.1× Marc's modified ringers [MMR]) and cell growth media (RPMI $+10 \%$ FBS) over $72 \mathrm{~h}$, where the results at the starting time for the highest concentration measured are reported in Table 1. PS$\mathrm{COOH}$ and $\mathrm{Fe}_{3} \mathrm{O}_{4}$-PEG NPs were stable, while QD and $\mathrm{Fe}_{3} \mathrm{O}_{4}-\mathrm{NH}_{2}$ showed extensive aggregation at this concentration, however, aggregation was less extensive at lower concentrations for both NPs, demonstrating that further biological investigation was possible for all the NPs selected. NP hydrodynamic sizes in the differ-

\begin{tabular}{|c|c|c|c|c|c|c|c|c|}
\hline \multirow[t]{2}{*}{ NP } & \multirow[t]{2}{*}{ TEM $(\mathrm{nm})$} & \multicolumn{2}{|c|}{ Water/PBS } & \multirow{2}{*}{$\begin{array}{l}\text { Zeta potential } \\
(\mathrm{mV})\end{array}$} & \multicolumn{2}{|c|}{ RMPI-1640 10\% FBS } & \multicolumn{2}{|c|}{$0.1 \times M M R$} \\
\hline & & HDS (nm) & PDI & & HDS (nm) & PDI & HDS (nm) & PDI \\
\hline QD & $4.5 \pm 2.0$ & $21.4 \pm 1.5$ & 0.1 & $-27.4 \pm 0.0$ & $107.5 \pm 1.2$ & 0.7 & $122 \pm 1.5$ & 0.1 \\
\hline PEG- $\mathrm{Fe}_{3} \mathrm{O}_{4}$ & $6.4 \pm 1.2$ & $21.9 \pm 0.1$ & 0.2 & $-3.9 \pm 0.8$ & $32.9 \pm 3.0$ & 0.2 & $22.1 \pm 0.9$ & 0.2 \\
\hline PS-COOH & $22.6 \pm 5.6$ & $34.5 \pm 0.7$ & 0.2 & $-37.2 \pm 2.0$ & $75.4 \pm 0.7$ & 0.2 & $34.7 \pm 0.7$ & 0.2 \\
\hline $\mathrm{NH}_{2}-\mathrm{Fe}_{3} \mathrm{O}_{4}$ & $11.3 \pm 2.9$ & $90.0 \pm 0.5$ & 0.2 & $+30.3 \pm 3.8$ & $294.0 \pm 2.3$ & 0.4 & $2268 \pm 96$ & 0.2 \\
\hline
\end{tabular}


ent environments were monitored over the experimental time for biological analysis and remained consistent as shown in Supplementary Figure 2B.

\section{Cytotoxicity assessment analysis}

We used a diverse array of mammalian cell types for cytotoxicity analysis (A549 [lung adenocarcinoma], SK-MEL-28 [melanoma] and MDCK [immortalized kidney] cells; that represent commonly available lines), which were exposed to varying concentrations of NPs over $72 \mathrm{~h}$. After NP stimulation, trypan blue exclusion assay, MTT assay and protein expression of full and cleaved poly (ADP-ribose) polymerase-1 (PARP-1) were performed to evaluate cytotoxic effects. Figure 2 shows the cytotoxic effects the NP panel in the three cell types, as a function of exposure concentration expressed as $\mathrm{NP} / \mathrm{ml}$ (for clarity analog graphs are reported vs concentration with different metrics $[\mathrm{w} / \mathrm{v}$ and surface area/v] shown in Supplementary Figure 3, with representative images of the treated cells at the highest concentration of NP treatment shown in Supplementary Figure 4). As expected, QDs were highly toxic in all cell types for concentrations $>10^{14} \mathrm{NP} / \mathrm{ml}$, which corresponds to a weight concentration of $0.1 \mu \mathrm{g} / \mathrm{ml}$. The MTT results showed that exposure to the highest concentrations of $\mathrm{Fe}_{3} \mathrm{O}_{4}-\mathrm{NH}_{2}$ and PS-COOH NPs on MDCK cells resulted in a $40 \%$ reduction in cell viability when compared with the other lines, while trypan blue results also showed reduced cell viability for the highest concentration of $\mathrm{Fe}_{3} \mathrm{O}_{4}-\mathrm{NH}_{2}$. PARP-1, activated by the production of reactive oxygen species (ROS), is a substrate for active cysteinyl-aspartate protease cleavage and is a marker of apoptotic cell death [29]. Previous studies have suggested an increase in ROS production after exposure to nanomaterials [30-32]. We investigated PARP-1 cleavage in the cells in response to NP treatment and found that only QDs induced apoptosis in cells at a comparable concentration to that of the cytotoxic drug, cisplatin, while no cleaved PARP-1 was observed in cells incubated with the other NPs (Figure 2C). Taken together these in vitro findings show that QDs induced high levels of cytotoxicity in mammalian cells compared with the other NPs tested.

\section{Xenopus laevis as a multiparametric nanotoxicity assessment tool}

Xenopus laevis embryos at different stages of development were exposed to varying concentrations of NPs and morphological scoring of an array of phenotypic abnormalities was carried out (Figure $3 \mathrm{~A}$ \& Supplementary Figure 5). Phenotypic abnormalities were scored and used to assess the NP effect on the development of 30 embryos at all three of the selected stages. Common abnormalities recorded included; edema, blistering, eye deformities, loss of melanocytes, tail loss, stunted growth, axial defects such as bent spines, degradation of tissue and developmental delay (Figure 3A \& B \& Supplementary Figure 5). Based on these abnormalities embryos were scored collectively as nonabnormal (healthy), abnormal or dead. By enabling all abnormalities to be marked in one category, simplifies the scoring system and keeps subjectivity between users to a minimum. Gastrulation occurs at an early phase of vertebrate development (in Xenopus at NF stage 10) and is a highly sensitive time to environmental changes during embryonic development, so to assess NP effects during this phase of development, embryos were exposed to the NPs at NF stage 4 and left to develop until NF stage 38 (Figure 3C). Another critical developmental process is neurulation, which occurs before organogenesis and gives rise to precursor tissues of the spinal cord, brain and neural crest [33]. To assess NP effects during neurulation and before organogenesis, embryos were exposed to the NPs at NF stage 15 and left to develop until NF stage 38 (Figure 3D). Finally, for in vivo embryonic systems that can more accurately represent an adult system, embryos were exposed to NPs at tadpole stages during organogenesis, specifically at NF stage 38-45 (Figure 3B \& E). QDs showed severe toxicity in X. laevis embryos at all stages, which is in good agreement with mammalian developmental systems [34], and our cytotoxicity data (Figure 2). The other NPs had limited toxicity, with the $\mathrm{Fe}_{3} \mathrm{O}_{4}-\mathrm{NH}_{2}$ and PS-COOH NPs showing toxic effects only at higher concentrations, while the $\mathrm{Fe}_{3} \mathrm{O}_{4}$-PEG NPs (synthesized in our laboratory as potential theranostic NPs), showed no toxicity at all stages, which is also in accordance with our in vitro findings (Figure 2).

We wanted to check that NPs exhibiting low-tono toxicity in $X$. laevis embryos (iron oxide and PSCOOH NPs) were taken up into the embryos following exposure. Embryo uptake by the iron oxide NPs and PS-COOH NPs was monitored by TEM imaging of embryo sections at NF stage 45 (Supplementary Figure 6) and fluorescence microscopy (FM) of live embryos at NF stage 45 (Supplementary Figure 7), respectively. TEM analysis demonstrated the presence of the NPs in embryo tissues for both iron oxide NPs (Supplementary Figure 6). FM of intact embryos treated with PS-COOH NPs permitted us to detect their presence within the embryos, where NP uptake was proportional to exposure (Supplementary Figure 7). Moreover, videos (Movie) of anesthetized embryos showed PS-COOH NPs (or agglomerates) moving through embryonic intersomatic blood vessels (from which time frame stills over $0.70 \mathrm{~s}$ have been extracted and are shown in Supplementary Figure 7B). Importantly, 

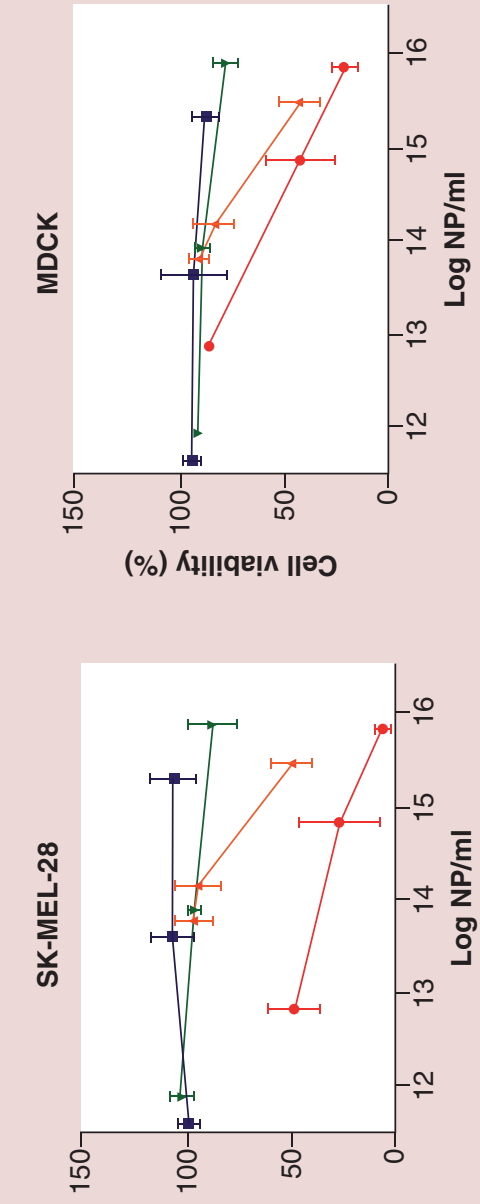

(\%) К‼!qe!ฺ ॥əว

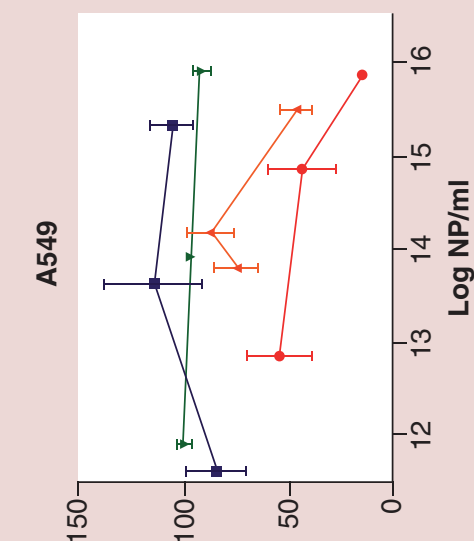

(४)

(\%) Кห!!!qघ!ก ॥əว

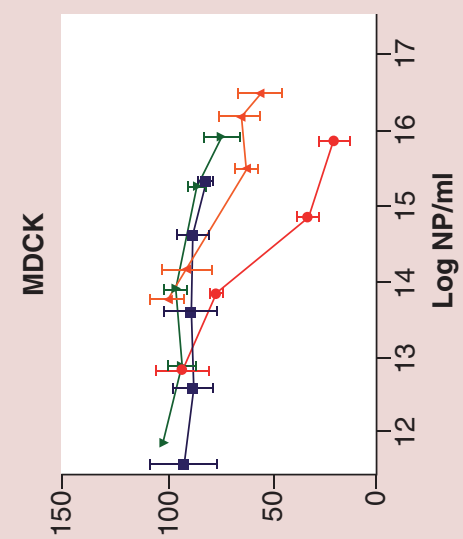

(\%) К‼!qघ!^ ||əว

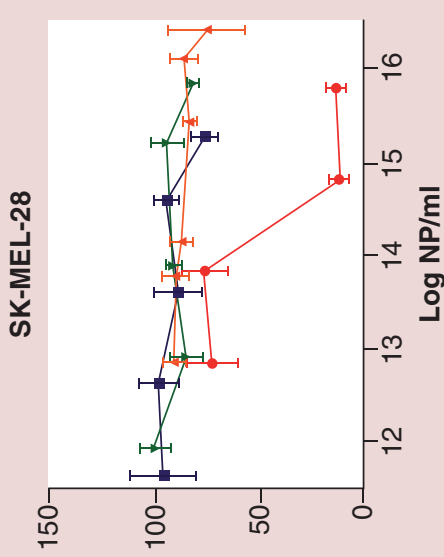

(\%) К‼!qए! ^ ||əว

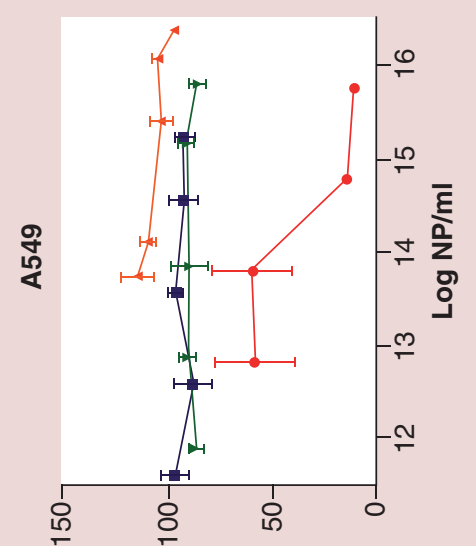

(9)

(\%) К‼!qอ! ॥ ||əว

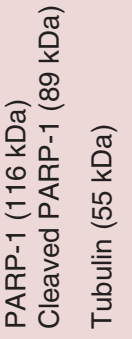

ปั

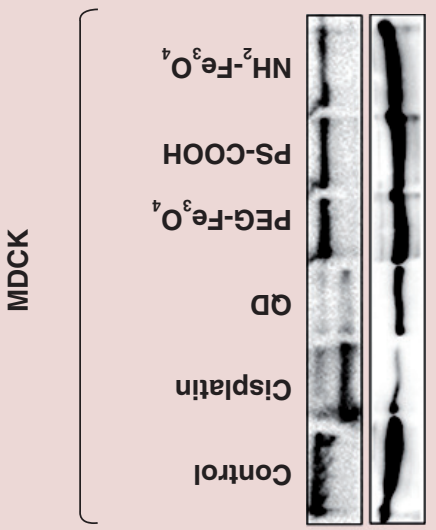

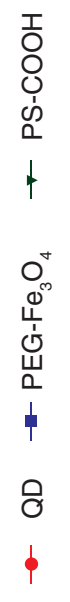

离
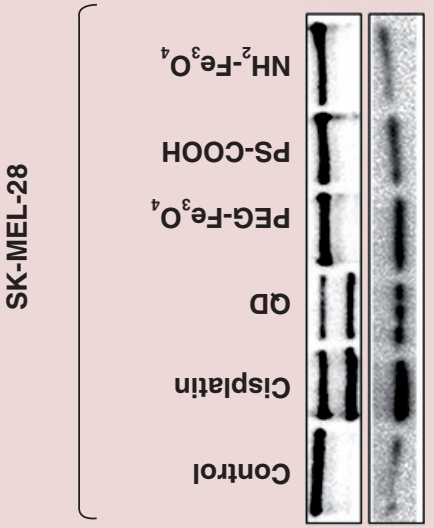

过

(2)

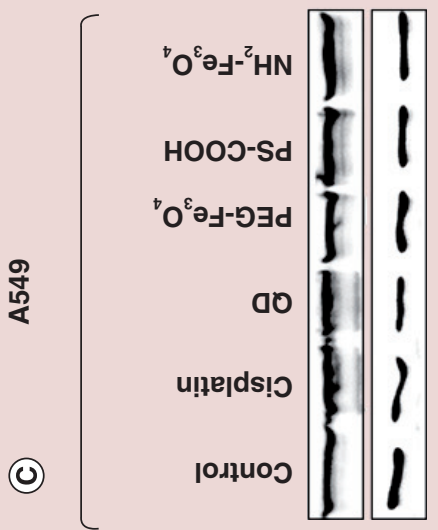


Figure 2. Evaluation of nanoparticle cytotoxicity (please see facing page). (A \& B) A549, SK-MEL-28 and MDCK cell lines were exposed to varying concentrations of QD, $\mathrm{PEG}-\mathrm{Fe}_{3} \mathrm{O}_{4}, \mathrm{PS}-\mathrm{COOH}$ and $\mathrm{NH}_{2}-\mathrm{Fe}_{3} \mathrm{O}_{4}$. After $72 \mathrm{~h}$ stimulation with NPs, trypan blue exclusion assay (A) and MTT assay (B) was performed to assess cell viability. Values represent mean \pm SEM. MTT data also represented as alternative concentration indices (Supplementary Figure 3). (C) Protein expression of full length and cleaved PARP-1 in mammalian cell lines. Cells were stimulated for $24 \mathrm{~h}$ with $70 \mu \mathrm{M}$ cisplatin (positive control), $10^{15.8} \mathrm{NP} / \mathrm{ml}$ QD, $10^{15.3} \mathrm{NP} / \mathrm{ml} \mathrm{PEG}-\mathrm{Fe}_{3} \mathrm{O}_{4^{\prime}}, 10^{15.9} \mathrm{NP} / \mathrm{ml} \mathrm{PS}-\mathrm{COOH}$ and $10^{15.5} \mathrm{NP} / \mathrm{ml} \mathrm{NH}_{2}-$ $\mathrm{Fe}_{3} \mathrm{O}_{4}$. Control cells were vehicle treated. $\beta$-tubulin was used as a loading control.

NP: Nanoparticle; QD: Quantum dot.

these data show that the NPs used in this study are readily taken up by the $X$. laevis embryos.

\section{Comparison of cytotoxicity \& $X$. laevis data for hazard ranking of NPs}

We developed a logical ranking system for correlating cytotoxicity and $X$. laevis results, to provide an overall hazard score from each assay for the investigated NPs (Tables 2 \& 3). For the cytotoxicity data the hazard score was obtained for the highest NP concentration, while for the $X$. laevis analysis we only took into account the results generated from the tadpole stage (Figure $3 \mathrm{E}$; NF 38-45, when the embryo has fully formed organs and therefore the evaluation of nanotoxicity is more physiologically relevant to adult tissues). The obtained hazard indices are reported in Tables 2 \& 3, which evaluates correlations between in vitro and in vivo results. The assays fully agreed on the evaluation of the toxicity for the highly toxic QDs that scored for severe toxic effects in all assays, as well as for the two iron oxide NPs that showed limited toxicity. However, PS-COOH NPs did not affect cell viability by the in vitro assays (Figure 2), yet exhibited toxicity effects at high concentrations as well as some moderate toxicity at lower concentrations in Xenopus (Figure 3). This suggests that the introduction of a $X$. laevis sampling test early on in NP development could help to identify false negatives for toxicity assessment produced by cell-based assays.

\section{Assessment of NP safety in a mammalian system}

In our protocol (Figure 1) if NP-induced developmental defects are observed in the $X$. laevis model, the NP will not progress to further assessment, rather only those nanoformulations that give no-to-low toxicity will progress to evaluation in small rodent models (in our data this was the two iron oxide NPs; Figures 2 \& 3 \& Tables 2 \& 3). To validate the low-to-no toxic prediction of the iron oxide NPs, we administered these two NPs in mice to assess toxicity effects on the tissues where they accumulated (the target organs). For iron oxide core NPs, murine target organs could be easily identified using MRI analysis. MRI analysis showed that in T2-weighed MRI coronal slices from epigastric and mesogastric regions, both iron oxide NPs accumulated in the liver and kidneys of the NPtreated animals compared with vehicle-treated controls
(Figure 4A \& B). Importantly, postmortem histological sections from the tissues where these NPs accumulated (the liver and kidneys) demonstrated not only that the iron distribution (as assessed by Perl's staining) corroborated the MRI findings, but importantly also failed to reveal any evidence of morphological tissue toxicity (Figure 4C) highlighting that these NPs exhibit littleto-no toxicity in mammalian tissues. These findings show that $X$. laevis embryos are a useful tool to predict NP safety prior to administration and further testing in mammalian models.

\section{Discussion \& conclusion}

With the growth of nanomedicines as therapies for disease management in the clinic, comes an ever increasing need to effectively assess how nano-sized therapeutics can effect biological systems and, in particular, systemic toxicity mechanisms [35]. As such, there has emerged a need for models that can produce effective toxicity data as a transition between $2 \mathrm{D}$ in vitro cell culture assays and expensive, often time-consuming in vivo mammalian models.

An alternative approach to mimic in vivo conditions has been to develop $3 \mathrm{D}$ and coculture in vitro cell-based models that better represent the organization of tissues compared with conventional 2D monocultures [36-41]. However, these tissue mimetic models are not without their limitations as they fail to recapitulate the complete systemic interactions present between organ systems in vivo, but rather focus on the development of individual, tissue-specific models. An early vertebrate developmental model can provide a complete in vivo model system, but with the added advantage of being a rapid toxicity assessment tool. Specifically, we have proposed the use of $X$. laevis as a readily available laboratory model to develop such a nanotoxicity screening tool (Figure 1). The protocol does not need to be limited to the exclusive use of Xenopus embryos, but rather can be easily extended to other commonly used developmental models such as the zebrafish model [11,42-44]. Amphibians share physiological traits common to all vertebrates, including mammals. Specific advantages of Xenopus as a model include; permeable skin, that they are tetrapods (therefore developing lungs and limbs), possessing all additional organs/tissues most commonly affected in human diseases (skin, sensory organs, lymphatic, nervous systems, kidneys, GI tract, 
(A)
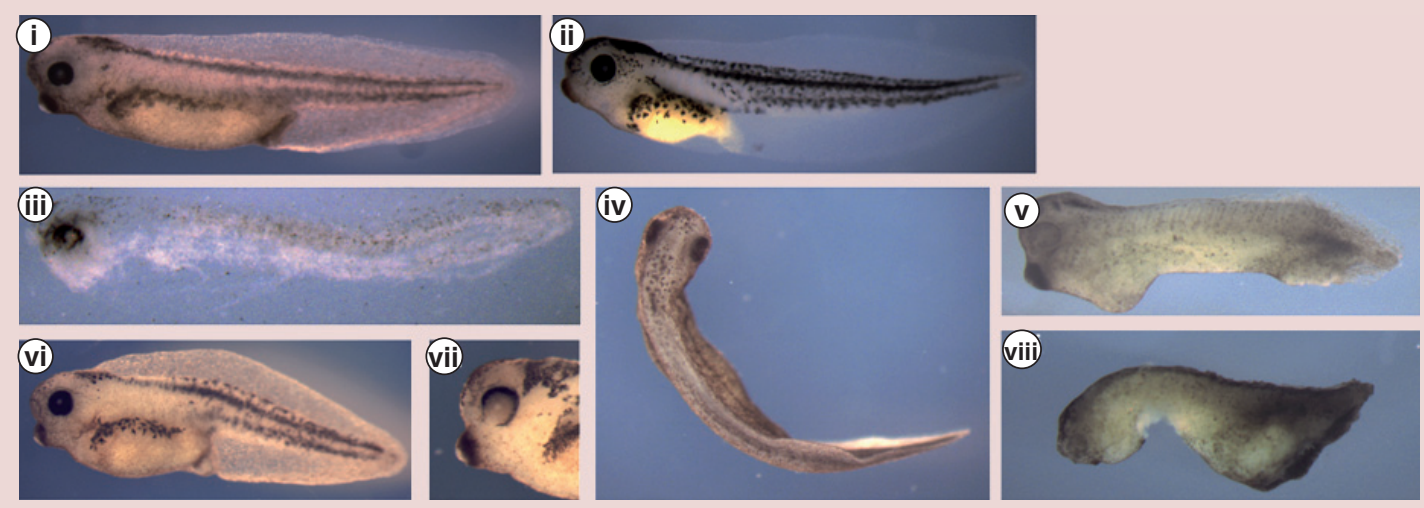

(B)

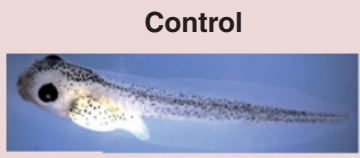

QD
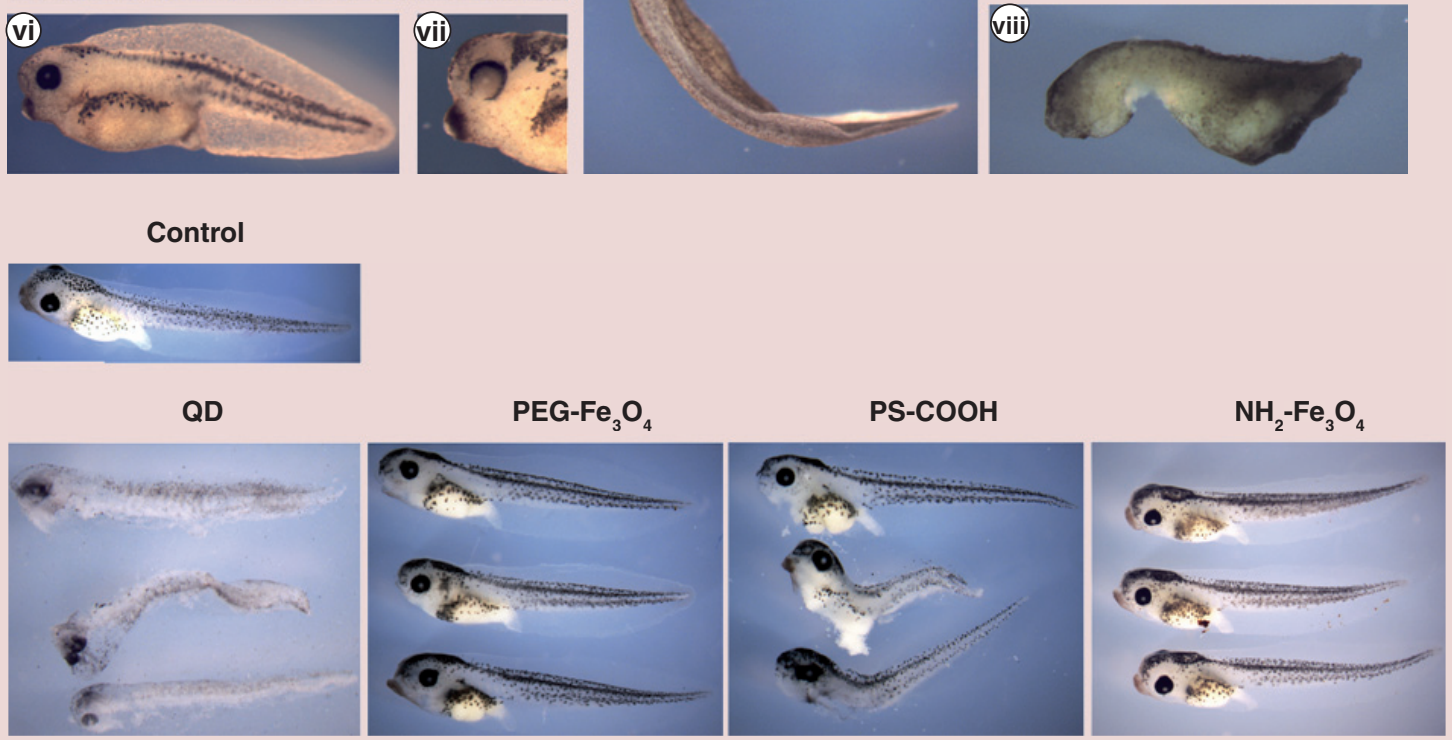

(C)

QD

PEG-Fe ${ }_{3} \mathrm{O}_{4}$

PS-COOH

$\mathrm{NH}_{2}-\mathrm{Fe}_{3} \mathrm{O}_{4}$
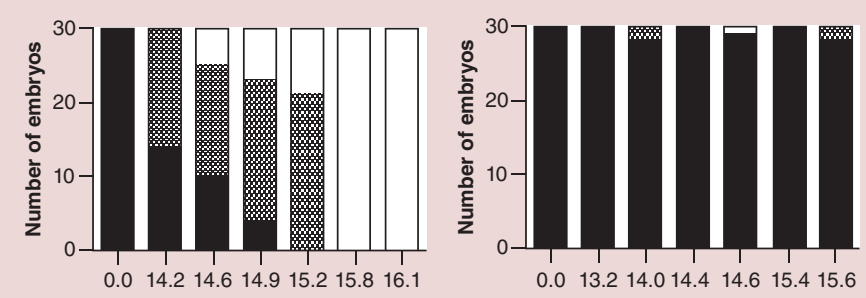

Log NP/ml

Log NP/ml

(D)

\begin{tabular}{cr} 
No abnormalities Abnormalities & $\square$ Dead \\
\hline QD & PEG-Fe $\mathbf{F}_{3} \mathbf{O}$
\end{tabular}
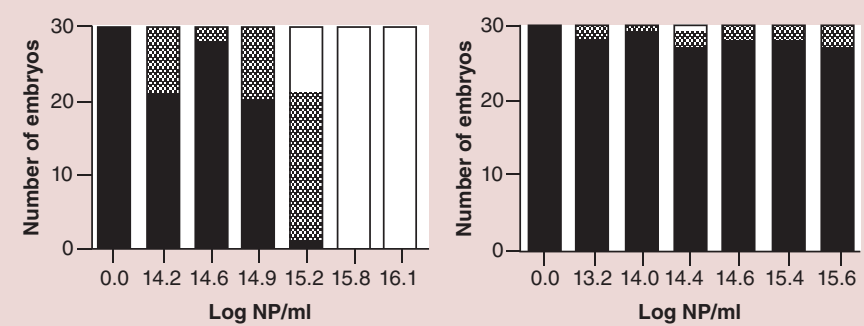

$\log \mathrm{NP} / \mathrm{ml}$
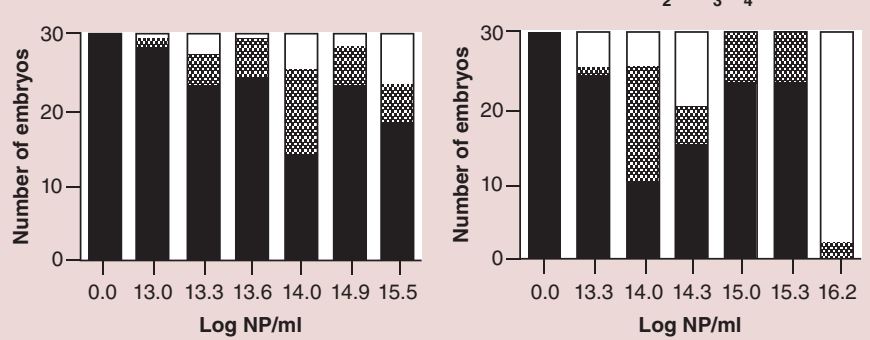

No abnormalities $\quad$ Abnormalities $\square$ Dead

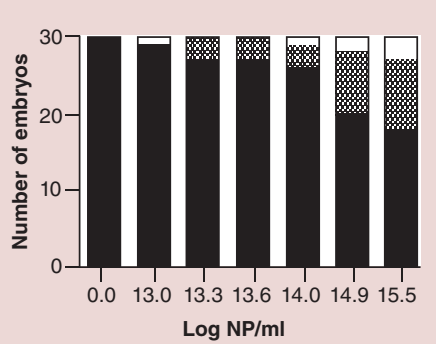

$\mathrm{NH} 2-\mathrm{Fe}_{3} \mathrm{O}_{4}$

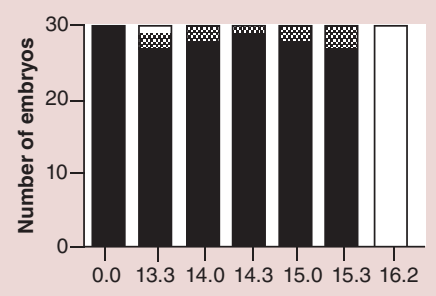

Log NP/ml 


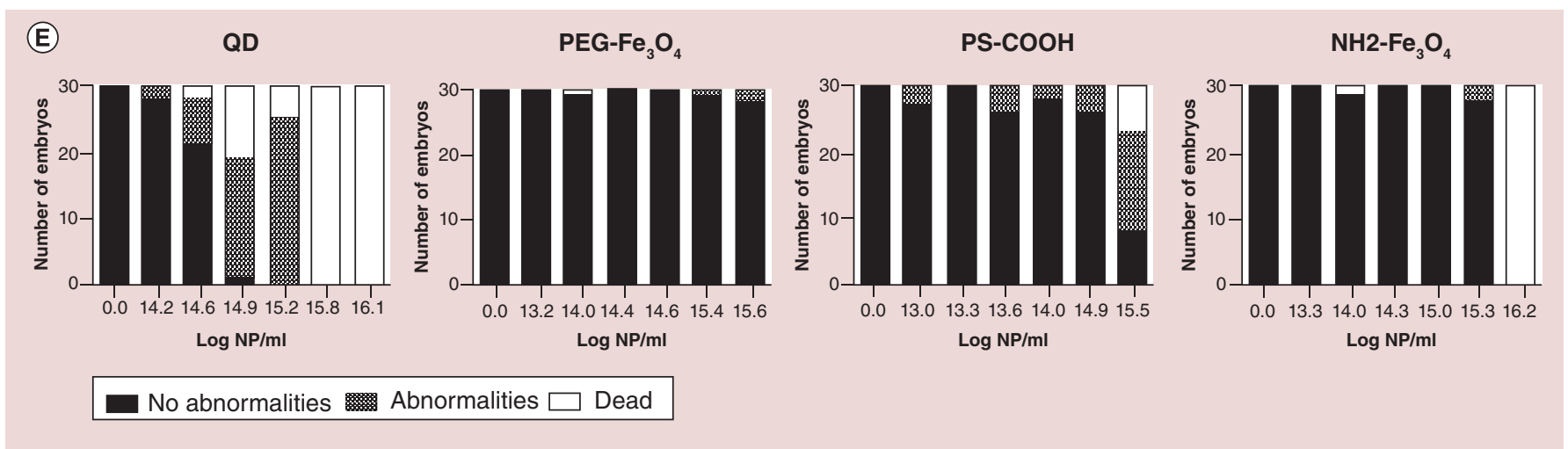

Figure 3. Xenopus laevis nanotoxicity phenotypic assay (for [A-D], please see facing page; for [E], please see above). (A) Representative images from the $X$. laevis phenotypic assay. (Ai) Control NF stage 38 embryo. (Aii) Control NF stage 45 embryo. (Aiii) embryo exposed to $10^{15.8} \mathrm{NP} / \mathrm{ml}$ QD at NF stage 38 and fixed at NF stage 45, all embryos were dead. (Aiv) Dorsal view of $X$. laevis with bent tail after exposure to $10^{14.2} \mathrm{NP} / \mathrm{ml}$ QD. (Av \& Aviii)X. laevis exposed to $10^{15.8} \mathrm{NP} / \mathrm{ml}$ QD at NF stage 4 and fixed when control embryos reached NF stage 38. Abnormalities include eye deformities, stunted growth/development, edema, blistering and melanocyte deformities. (Avi \& Avii) Embryo exposed to $10^{14.2} \mathrm{NP} / \mathrm{ml}$ QD. Abnormalities include stunted growth, bent spin and loss of pigmentation in the eye. (B) Representative images embryos exposed to $10^{15.8} \mathrm{NP} / \mathrm{ml}$ QD, $10^{15.6} \mathrm{NP} / \mathrm{ml} \mathrm{PEG-Fe} \mathrm{O}_{3} \mathrm{O}_{4}, 10^{15.5} \mathrm{NP} / \mathrm{ml} \mathrm{PS}-\mathrm{COOH}$ and $10^{15.3} \mathrm{NP} / \mathrm{ml} \mathrm{NH2}-\mathrm{Fe}_{3} \mathrm{O}_{4}$. Embryos were developed in $0.1 \times \mathrm{MMR}$ and NP solution at different stages and fixed. The embryos were then analyzed for any developmental abnormalities or death. (C-E) Quantification of embryonic abnormalities. Histograms shown are of 30 embryos at each concentration of QD, PEG- $\mathrm{Fe}_{3} \mathrm{O}_{4}, \mathrm{PS}-\mathrm{COOH}$ and $\mathrm{NH}_{2}-\mathrm{Fe}_{3} \mathrm{O}_{4}$. X. laevis assessed as healthy (no abnormalities), developmental defects (abnormalities) and death (dead) as indicated, at different concentrations of NPs. Developmental defects include eye malformations, bent spine/tail, edema, blistering and stunted growth, as shown in (A). (C) Embryos exposed at NF stage 4 and fixed at NF stage 38, (D) embryos exposed at NF stage 15 and fixed at NF stage 38 and (E) embryos exposed at NF stage 38 and fixed at NF stage 45.

NP: Nanoparticle; QD: Quantum dot.

cardiovascular, hepatic and circulatory systems), they are the highest evolutionary order providing free-living embryos to permit screening in multiwell formats, and in earlier life stages prior to the onset of independent feeding (before NF 45), they are described under the EU directive as not protected as nonhuman vertebrate models; thus making them highly amenable for toxicity testing procedures, as previously reviewed [18].

It is important that the physicochemical properties of the NPs are tested in the relevant biological fluids prior to toxicity assessment, so that the behavior of the NPs are well understood before proceeding to biological testing, enabling us to infer whether or not toxicity profiles are in fact dependent on the nanomaterial itself or NP aggregation. For example, the high salt concentration in the X. laevis embryo MMR buffer, affected the stability of electrostatically stabilized NPs such as QD and $\mathrm{Fe}_{3} \mathrm{O}_{4}-\mathrm{NH}_{2}$ (Table 1), while the presence of proteins with further formation of protein-NP complexes [45] reduces aggregation in such NPs, suggesting that once in vivo, following initial exposure to aggregating NPs, this aggregation will likely be reduced in biological fluids.

In this study, we selected four NPs that span a variety of materials and presented different toxicity indices to test the suitability of this as a nanotoxicity protocol. $\mathrm{Fe}_{3} \mathrm{O}_{4}-\mathrm{NH}_{2}$ NPs were found, according to our methodology, as having low-to-no-toxicity and further tested in mice with no evidence of any major acute toxicity effect. We observed good agreement between in vitro and in vivo analysis for the nanomaterials tested, suggesting that there is a good correlation between nanotoxicity assessment in $X$. laevis and mammalian cells. The reputed toxic QD NPs and the iron oxide core NPs were ranked as toxic and low-to-no-toxicity, respectively, which is in agreement with data reported by others for similar NPs [46,47]. However, a significant contradiction in the ranking of the PS-COOH NPs was found between in vitro and in vivo results. Specifically, cytotoxicity was not detected in the investigated concentration range by any of the cell-based assays used, while mortality and abnormalities were scored for the embryos at higher PS-COOH NP concentrations, thus highlighting the importance of a fully integrated cell line and $X$. laevis approach to accurately assess nanomaterial safety and to identify false negatives. The physical characterization of PS-COOH NPs in biological fluids did not show any agglomeration effects that could promote toxicity. However, there is experimental evidence in the literature of toxicity effects due to carboxylic surface functionalization of polystyrene NPs is related to interaction with the blood plasma proteins $[48,49]$. FM on live embryos (Movie) confirmed the presence of high concentrations of PS-COOH NPs in the X. laevis tissues. Therefore, a fundamental step in our protocol is the comparison between the in vitro cytotoxicity data and the in vivo findings in Xenopus (Figure 1). 
Table 2. Hazard score obtained from the cell assays and embryo analysis.

\begin{tabular}{|llll} 
Hazard & Hazard score & Cell viability (\%) & Healthy embryo (\%) \\
0 & 0 & $>76$ & $>76$ \\
\hline$x$ & 1 & $50-75$ & $50-75$ \\
\hline$x x$ & 2 & $<50$ & $<50$ \\
\hline
\end{tabular}

Moreover another toxicity aspect was tested, as the two chosen iron oxide NPs bearing specific surface functionalizations, showed different stability in the biological fluids at the highest concentration, where the $\mathrm{Fe}_{3} \mathrm{O}_{4}-\mathrm{NH}_{2} \mathrm{NPs}$ aggregated extensively. This concentration-dependent agglomeration was more pronounced in the MMR buffer than in cell growth media, promoting mortality of the embryos at the highest $\mathrm{Fe}_{3} \mathrm{O}_{4}-\mathrm{NH}_{2} \mathrm{NP}$ concentration, whereas no toxicity was observed for the lower concentrations at tadpole stages in the embryos (NF 38-45). This indicates that such a toxic effect was potentially related to the colloidal instability of the NPs rather than to the material composition of the NP itself. Instead, in vitro analysis provided mixed results depending on the cell line and of the assay that was used. Some toxicity was detected in the trypan blue exclusion assay at the highest concentration, which was not readily detectable in the MTT assay (Figure 2A \& B). Of note, PARP-1 cleavage assay (Figure 2C) showed unambiguously no apoptosis for all the treated cell lines at the highest NP concentration, highlighting that numerous cytotoxicity assays are required in combination to effectively assess NP toxicity. Furthermore, cell line choice for nanotoxicity assessment provides a bespoke feature of this assay, where cell lines can be selected that are most suitable for analyzing nanomaterials designed for specific biomedical purposes.

For the X. laevis studies, we developed a simplified scoring system of the embryos allowing us to easily and rapidly assess NP-mediated toxicity in embryos at differing developmental stages (Figure $3 \mathrm{C}-\mathrm{E}$ ). We found that embryos exposed to PS-COOH NPs showed some toxicity for all stages at higher concentrations, in particular at the earliest stage (NF 4-38), where toxicity was observed from concentrations $>10^{14} \mathrm{NP} / \mathrm{ml}$. Embryos exposed to $\mathrm{Fe}_{3} \mathrm{O}_{4}-\mathrm{NH}_{2}$ NPs showed toxicity at the earliest stage from concentrations $>10^{14} \mathrm{NP} / \mathrm{ml}$, while only at the highest NP concentration was $100 \%$ mortality observed at the other two stages of development. The severe toxicity observed at the highest concentration of $\mathrm{Fe}_{3} \mathrm{O}_{4}-\mathrm{NH}_{2} \mathrm{NPs}$ was related to the extensive aggregation of these NPs in MMR medium, which resulted in precipitation at high concentrations. However, at the latest stage (NF 38-45), for which the embryo has developed most of its organs, no toxicity was observed at all the other concentrations for $\mathrm{Fe}_{3} \mathrm{O}_{4}-\mathrm{NH}_{2}$ NPs. Generally, we can state that where the embryos developed in the presence of NPs, NF stage 4 to NF stage 38 showed more phenotypic abnormalities and death at lower NP concentrations, than embryos exposed at NF stages 15 and 38. It is of note that between NF 38-45 the gills and mouth are open providing, in addition to the porous skin, possible respiratory and oral tract routes of exposure as well [50].

NPs were more toxic to embryos in early development (4-38 and 15-38 NF stages; Figure 3), in particular at the earliest stage, although it is difficult to say if this is connected to the different phase of development, or due to the longer exposure time to the NPs in these animals. While the first two stages might not be adaptable as prognostic model for toxicity in mammals, they can be used to evaluate teratogenesis. A study on $X$. laevis embryos, in which NPs were microinjected between NF stage 1 and 3, has shown that nanodiamond NPs with carboxylic surface groups promoted teratogenesis at both gastrulation and neurulation stages [51]. Other studies on $X$. laevis of metal oxide $\mathrm{NPs}(\mathrm{CuO}, \mathrm{ZnO}$, etc.) have evaluated teratogenesis using the FETAX assay and reported major toxicity effects in the GI tract $[14,25,52]$. While FETAX focuses of teratogenic effects on midblastula stage embryos, we have demonstrated $X$. laevis as a versatile model that can be used to predict toxicity of nanomaterials beyond teratogenic effects.

Our protocol predicts that the combined cytotoxicity and $X$. laevis scores facilitate optimal prediction for toxicity in mammalian systems (Figure 1). Both iron core NPs gave a low hazard ranking for the cell culture

Table 3. Hazard score obtained from the cell assays and embryo analysis.

\begin{tabular}{llll} 
Nanoparticle & MTT & Trypan blue & Xenopus laevis \\
\hline Quantum dot & $\mathrm{xx}$ & $\mathrm{Xx}$ & $\mathrm{xx}$ \\
\hline $\mathrm{PEG}-\mathrm{Fe}_{3} \mathrm{O}_{4}$ & 0 & 0 & 0 \\
$\mathrm{PS}-\mathrm{COOH}$ & 0 & 0 & $\mathrm{xx}$ \\
$\mathrm{NH}_{2}-\mathrm{Fe}_{3} \mathrm{O}_{4}$ & 0 & 0 & 0 \\
\hline
\end{tabular}




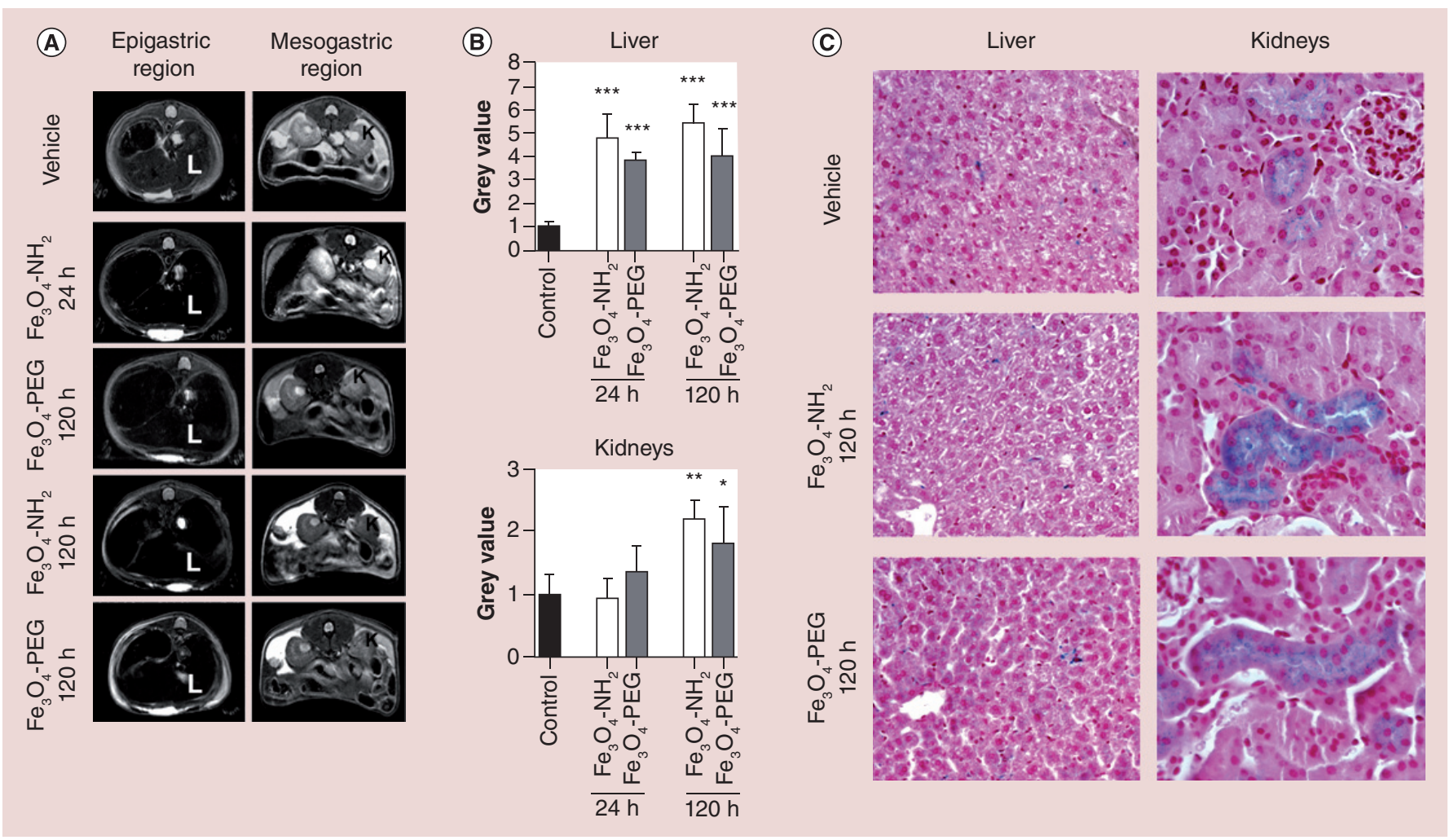

Figure 4. Assessment of iron oxide nanoparticles in a mammalian model. (A) Representative MRI images showing coronal slices corresponding to the epigastric (left column) and mesogatric region (right column). (B) Histograms showing the gray levels in liver (upper panel) and kidney (lower panel) measured from vehicle- (black bars), $\mathrm{Fe}_{3} \mathrm{O}_{4}-\mathrm{NH}_{2}$ nanoparticles (NPs) (white bars) and Fe $\mathrm{O}_{4}$ PEG NPs treated mice (gray bars) at 1 or 5 days after NP administration. Data are expressed as mean $\pm S D$. ${ }^{*} p<0.005 ; * * p<0.01, * * * p$ $<0.0001$ compared with the vehicle (Student's $t$-test). (C) Perl's stained tissue sections from target organs in treated animals. Tissues counter-stained with eosin. Representative images shown. Higher power images to highlight normal tissue structure in the NP treated animals are shown in Supplementary Figure 8.

K: Kidneys; L: Liver.

and embryo assessment protocols (Tables 2 \& 3). For this reason, we evaluated both these NPs in rodent models to confirm low toxicity. The other two NPs tested (PS$\mathrm{COOH}$ and QD NPs) caused toxicity in vivo and therefore in our protocol would not progress to rodent model testing (Figure 1). We intravenously injected $\mathrm{Fe}_{3} \mathrm{O}_{4} \mathrm{NPs}$ into mice and monitored where they accumulated in the animals using MRI to identify those organs exposed to the NPs. Darkening of signal was used as an indication of the presence of iron oxide NPs in organs, identifying the parenchyma of the kidneys and liver as target tissues for these NPs. Quantification of gray values confirmed the MRI scanning and suggests a prolonged permanence of NPs in liver, but potential clearance in the kidneys. Histochemical staining of the liver and kidneys was consistent with the MRI results, where crucially no histopathologies were induced in these organs by prolonged NP exposure. Positive Perl's staining was evident in liver of both $\mathrm{Fe}_{3} \mathrm{O}_{4}$-PEG and $\mathrm{Fe}_{3} \mathrm{O}_{4}-\mathrm{NH}_{2}$ treated animals, which was detected as a cytoplasmic granular blue staining of scattered interstitial cells. In renal tissue of both $\mathrm{Fe}_{3} \mathrm{O}_{4}-$ PEG and $\mathrm{Fe}_{3} \mathrm{O}_{4}-\mathrm{NH}_{2}$ treated animals staining within tubular epithelial cells was observed (Figure 4C). Neither presented with gross histopathological defects, demonstrating there was no cytotoxic effects of the iron core NPs in these organs. Crucially these results validated our findings from the integrated cell line and $X$. laevis toxicity assessment protocol, showing that the iron oxide NPs did not induce major effects in mammalian models.

\section{Conclusion}

Overall, we have developed a powerful integrative tool for screening nanomaterials that can work as bridge between in vitro and in vivo analysis for nanotoxicity. Our data demonstrate the flexibility of this multimodal preclinical assessment tool in the hazard assessment of nanomaterials, during the early stages of their production for biomedical applications. As such, functional modifications made to nanotherapeutics to enhance their efficacy, can be quickly analyzed using the protocol developed here for nanotoxic effects identified, which can then be addressed at an early stage in development of the nanotherapy, prior to mammalian testing. This allows the rapid and cheap identifica- 
tion of possible NP-induced toxicities that may not be detectable through conventional cytotoxicity assays, at an early stage in the development of nanotherapeutics.

\section{Future perspective}

With the increase in development of nanotherapeutics and a lack of correlation between in vitro and in vivo safety assessment, there is now (more than ever) a need to develop standardized toxicity assessment protocols. We envisage that early developmental vertebrate models, such as Xenopus, can be easily integrated into a standardized safety protocol for novel nanomaterial testing, minimizing the time and cost of using mouse models and other higher vertebrates at an early stage in nanotherapeutic design. Furthermore, information gathered from Xenopus will help to understand the behavior of new nanomedicines in whole organism systems.

\section{Supplementary data}

To view the supplementary data that accompany this paper, please visit the journal website at: www.futuremedicine.com/ doi/full/10.2217/NNM.15.219

\section{Acknowledgements}

The authors would like to acknowledge $Y$ Chou (School of Chemistry, UEA) for providing us with the QD NPs for this study and G Harrison for technical support with the cytotoxicity assessment methods. Furthermore, the authors would like to thank A Hendry for his support with the X laevis work. The authors would also like to acknowledge C Elgy and P Stanley, FENAC (Facility for Environmental Nanoscience Analysis and
Characterization), for technical assistance with the sectioning and embedding of Xenopus laevis embryos for TEM.

Financial \& competing interests disclosure

This work was supported by funds from The British Skin Foundation, The Royal Society and UEA start up funds to $V$ Sherwood and FB Bombelli. FB Bombelli would like to thank for additional financial support RegioneLombardia (Fondo per lo Sviluppo e la Coesione - FAS 2007-2013). V Sherwood is supported by a CRUK programme grant awarded to the CRUKSkin Tumour Laboratory, Medical School, University of Dundee. The authors have no other relevant affiliations or financial involvement with any organization or entity with a financial interest in or financial conflict with the subject matter or materials discussed in the manuscript apart from those disclosed.

No writing assistance was utilized in the production of this manuscript.

\section{Ethical conduct of research}

The authors state that they have obtained appropriate institutional review board approval or have followed the principles outlined in the Declaration of Helsinki for all human or animal experimental investigations. In addition, for investigations involving human subjects, informed consent has been obtained from the participants involved.

\section{Open access}

This article is distributed under the terms of the Creative Commons Attribution License 4.0 which permits any use, distribution, and reproduction in any medium, provided the original author(s) and the source are credited. To view a copy of the license, visit http://creativecommons.org/licenses/by/4.0/

Executive summary

\section{Xenopus laevis as a multiparametric nanotoxicity assessment too}

- We proposed $X$. laevis as a readily available laboratory model to develop a nanotoxicity screening tool and developed a simplified scoring system allowing us to easily and rapidly assess nanoparticle (NP) mediated toxicity in embryos at differing developmental stages.

\section{Comparison of cytotoxicity \& X. laevis data for hazard ranking of NPs}

- The total scoring system combines cytotoxicity and $X$. laevis results for four different NPs for which a physicalchemical characterization in the biological environment was also performed

\section{Assessment of NP safety in a mammalian system}

- NPs with a low hazard ranking for the cell culture and embryo assessment protocols did not show major histopathologies in the organs where they were accumulated in mice, indicating a good prediction of in vivo NP effects.

- We developed a fast and cheap tool for screening nanomaterials that can work as bridge between in vitro and in vivo analysis for early stage screening of nanotoxicity.

\section{References}

Papers of special note have been highlighted as:

• of interest; $\bullet$ of considerable interest.

1 Lee DE, Koo H, Sun IC, Ryu JH, Kim K, Kwon IC. Multifunctional nanoparticles for multimodal imaging and theragnosis. Chem. Soc. Rev. 41(7), 2656-2672 (2012).
2 Lewinski N, Colvin V, Drezek R. Cytotoxicity of nanoparticles. Small 4(1), 26-49 (2008).

3 Nystrom AM, Fadeel B. Safety assessment of nanomaterials: implications for nanomedicine. J. Control. Release 161(2), 403-408 (2012)

4 Hillegass JM, Shukla A, Lathrop SA, Macpherson MB, Fukagawa NK, Mossman BT. Assessing nanotoxicity 
in cells in vitro. Wiley Interdiscip. Rev. Nanomed. Nanobiotechnol. 2(3), 219-231 (2010).

5 Duncan R. Nanomedicine(s) and their regulation: an overview. In: Handbook of Safety Assessment of Nanomaterials - From Toxicological Testing to Personalized Medicine. Fadeel B (Eds). Pan Stanford Publishing Pte Ltd (2013).

- Review of the challenges ahead for the safety of nanomedicines and their interaction in biological environments.

6 Duncan R, Gaspar R. Nanomedicine(s) under the microscope. Mol. Pharm. 8(6), 2101-2141 (2011).

7 Venditto VJ, Szoka FC Jr. Cancer nanomedicines: so many papers and so few drugs! Adv. Drug Deliv. Rev. 65(1), 80-88 (2013).

8 Bawarski WE, Chidlowsky E, Bharali DJ, Mousa SA. Emerging nanopharmaceuticals. Nanomedicine 4(4), 273-282 (2008).

9 The International Council for Harmonisation of Technical Requirements for Pharmaceuticals for Human Use (ICH). www.ich.org

10 Krug HF, Wick P. Nanotoxicology: an interdisciplinary challenge. Angew. Chem. Int. Ed. Engl. 50(6), 1260-1278 (2011).

11 George S, Xia T, Rallo R et al. Use of a high-throughput screening approach coupled with in vivo zebrafish embryo screening to develop hazard ranking for engineered nanomaterials. ACS Nano 5(3), 1805-1817 (2011).

-• Combining in vitro high-throughput toxicity assessment with a vertebrate model, Zebrafish, to create a comprehensive screening tool for engineered nanomaterials.

12 Joris F, Manshian BB, Peynshaert K, De Smedt SC, Braeckmans K, Soenen SJ. Assessing nanoparticle toxicity in cell-based assays: influence of cell culture parameters and optimized models for bridging the in vitro-in vivo gap. Chem. Soc. Rev. 42(21), 8339-8359 (2013).

13 Liu Y, Liu B, Feng D et al. A progressive approach on zebrafish toward sensitive evaluation of nanoparticles' toxicity. Integr. Biol. (Camb.) 4(3), 285-291 (2012).

14 Bacchetta R, Moschini E, Santo N et al. Evidence and uptake routes for zinc oxide nanoparticles through the gastrointestinal barrier in Xenopus laevis. Nanotoxicology 8(7), 728-744 (2014).

15 Rizzo LY, Golombek SK, Mertens ME et al. In vivo nanotoxicity testing using the zebrafish embryo assay. J. Mater. Chem. B 1, doi:10.1039/C3TB20528B (2013).

16 Leconte I, Mouche I. Frog embryo teratogenesis assay on Xenopus and predictivity compared with in vivo mammalian studies. Methods Mol. Biol. 947 403-421 (2013).

-• The use of Xenopus to assess teratogenic affects of potential pharmacutical compounds.

17 Wheeler GN, Liu KJ. Xenopus: an ideal system for chemical genetics. Genesis 50(3), 207-218 (2012).

18 Schmitt SM, Gull M, Brandli AW. Engineering Xenopus embryos for phenotypic drug discovery screening. Adv. Drug Deliv. Rev. 69-70, 225-246 (2014).
19 Strober W. Trypan blue exclusion test of cell viability. In Current Protocols in Immunology. Coligan JE (Ed.). John Wiley \& Sons, Inc., A313.1-A313.2 (2001).

20 Berridge MV, Tan AS. Characterization of the cellular reduction of 3-(4,5-dimethylthiazol-2-yl)2,5-diphenyltetrazolium bromide (MTT): subcellular localization, substrate dependence, and involvement of mitochondrial electron transport in MTT reduction. Arch. Biochem. Biophys. 303(2), 474-482 (1993).

21 Sherwood V, Chaurasiya SK, Ekstrom EJ et al. WNT5Amediated beta-catenin-independent signalling is a novel regulator of cancer cell metabolism. Carcinogenesis 35(4), 784-794 (2014).

22 Tomlinson ML, Rejzek M, Fidock M, Field RA, Wheeler GN. Chemical genomics identifies compounds affecting Xenopus laevis pigment cell development. Mol. Biosyst. 5(4), 376-384 (2009).

23 Sherwood V, Manbodh R, Sheppard C, Chalmers AD. RASSF7 is a member of a new family of RAS association domain-containing proteins and is required for completing mitosis. Mol. Biol. Cell 19(4), 1772-1782 (2008).

24 Tarin D. Normal table of Xenopus laevis (Daudin). J. Anatomy 103(Pt 3), 578-578 (1968).

25 Bacchetta R, Tremolada P, Di Benedetto C et al. Does carbon nanopowder threaten amphibian development? Carbon 50(12), 4607-4618 (2012).

26 Bigini P, Diana V, Barbera $S$ et al. Longitudinal tracking of human fetal cells labeled with super paramagnetic iron oxide nanoparticles in the brain of mice with motor neuron disease. PLoS ONE 7(2), e32326 (2012).

27 Canzi L, Castellaneta V, Navone S et al. Human skeletal muscle stem cell antiinflammatory activity ameliorates clinical outcome in amyotrophic lateral sclerosis models. Mol. Med. 18, 401-411 (2012).

28 OECD Environment, Health and Safety Publications, Series on the Safety of Manufactured Nanomaterials No=59 Presented atJoint Meeting of the Chemicals Committee and the Working Party on Chemicals, Pesticides and Biotechnology 2015 (January).

29 Tewari M, Wolf FW, Seldin MF, O'shea KS, Dixit VM, Turka LA. Lymphoid expression and regulation of A20, an inhibitor of programmed cell death. J. Immunol. 154(4), 1699-1706 (1995).

30 Filippi C, Pryde A, Cowan P et al. Toxicology of $\mathrm{ZnO}$ and $\mathrm{TiO}$ nanoparticles on hepatocytes: impact on metabolism and bioenergetics. Nanotoxicology9(1), 126-134 (2015).

31 Hussain SM, Hess KL, Gearhart JM, Geiss KT, Schlager JJ. In vitro toxicity of nanoparticles in BRL 3A rat liver cells. Toxicol. In Vitro 19(7), 975-983 (2005).

32 Carlson C, Hussain SM, Schrand AM et al. Unique cellular interaction of silver nanoparticles: size-dependent generation of reactive oxygen species. J. Phys. Chem. B 112(43), 13608-13619 (2008).

33 Lowery LA, Sive H. Strategies of vertebrate neurulation and a re-evaluation of teleost neural tube formation. Mech. Dev. 121(10), 1189-1197 (2004). 
34 Chan WH, Shiao NH. Cytotoxic effect of CdSe quantum dots on mouse embryonic development. Acta Pharmacol. Sinica 29(2), 259-266 (2008).

35 Nel A, Xia T, Madler L, Li N. Toxic potential of materials at the nanolevel. Science 311(5761), 622-627 (2006).

36 Pampaloni F, Reynaud EG, Stelzer EHK. The third dimension bridges the gap between cell culture and live tissue. Nat. Rev. Mol. Cell Biol. 8(10), 839-845 (2007).

37 Muller L, Riediker M, Wick P, Mohr M, Gehr P, RothenRutishauser B. Oxidative stress and inflammation response after nanoparticle exposure: differences between human lung cell monocultures and an advanced three-dimensional model of the human epithelial airways. J. R. Soc. Interface 7, S27-S40 (2010).

38 Lee J, Lilly GD, Doty RC, Podsiadlo P, Kotov NA. In vitro toxicity testing of nanoparticles in $3 \mathrm{D}$ cell culture. Small 5(10), 1213-1221 (2009).

39 Movia D, Prina-Mello A, Bazou D, Volkov Y, Giordani S. Screening the cytotoxicity of single-walled carbon nanotubes using novel 3D tissue-mimetic models. ACS Nano 5(11), 9278-9290 (2011).

40 Astashkina AI, Jones CF, Thiagarajan G et al. Nanoparticle toxicity assessment using an in vitro 3-D kidney organoid culture model. Biomaterials 35(24), 6323-6331 (2014).

41 Smalley KM, Lioni M, Herlyn M. Life ins't flat: taking cancer biology to the next dimension. In Vitro Cell. Devel. Biol. Animal 42(8-9), 242-247 (2006).

42 Duan J, Yu Y, Shi $\mathrm{H}$ et al. Toxic effects of silica nanoparticles on zebrafish embryos and larvae. PLoS ONE 8(9), e74606 (2013).

43 Kim K-T, Zaikova T, Hutchison JE, Tanguay RL. Gold nanoparticles disrupt zebrafish eye development and pigmentation. Toxicol. Sci. 133(2), 275-288 (2013).
- Phenotypic toxicity study using embryos of a vertebrate model, Zebrafish, exposed to gold nanoparticles.

44 Zhu X, Zhu L, Duan Z, Qi R, Li Y, Lang Y. Comparative toxicity of several metal oxide nanoparticle aqueous suspensions to Zebrafish (Danio rerio) early developmental stage. J. Environ. Sci. Health Part A 43(3), 278-284 (2008).

45 Walczyk D, Bombelli FB, Monopoli MP, Lynch I, Dawson KA. What the cell "sees" in bionanoscience. J. Am. Chem. Soc. 132(16), 5761-5768 (2010).

46 Liu G, Gao J, Ai H, Chen X. Applications and potential toxicity of magnetic iron oxide nanoparticles. Small 9(9-10), 1533-1545 (2013).

47 Shiohara A, Hoshino A, Hanaki K, Suzuki K, Yamamoto K. On the cyto-toxicity caused by quantum dots. Microbiol. Immunol. 48(9), 669-675 (2004).

48 Clancy AA, Gregoriou Y, Yaehne K, Cramb DT. Measuring properties of nanoparticles in embryonic blood vessels: towards a physicochemical basis for nanotoxicity. Chem. Phys. Lett. 488(4-6), 99-111 (2010).

49 Oslakovic C, Cedervall T, Linse S, Dahlback B. Polystyrene nanoparticles affecting blood coagulation. Nanomedicine 8(6), 981-986 (2012).

50 Dickinson AJ, Sive H. Development of the primary mouth in Xenopus laevis. Dev. Biol. 295(2), 700-713 (2006).

51 Marcon L, Riquet F, Vicogne D, Szunerits S, Bodart J-F, Boukherroub R. Cellular and in vivo toxicity of functionalized nanodiamond in Xenopus embryos. J. Mater. Chem. 20, 8064-8069 (2010).

52 Bacchetta R, Santo N, Fascio U et al. Nano-sized CuO, $\mathrm{TiO}(2)$ and $\mathrm{ZnO}$ affect Xenopus laevis development. Nanotoxicology 6(4), 381-398 (2012). 